\title{
Streamer Characteristic and Breakdown in a Mineral Oil and a Synthetic Ester Liquid under DC Voltage
}

DOI:

10.1109/tdei.2018.006938

\section{Document Version}

Accepted author manuscript

Link to publication record in Manchester Research Explorer

\section{Citation for published version (APA):}

Xiang, J., Liu, Q., \& Wang, Z. (2018). Streamer Characteristic and Breakdown in a Mineral Oil and a Synthetic Ester Liquid under DC Voltage. IEEE Transactions on Dielectrics and Electrical Insulation, 1636-1643.

https://doi.org/10.1109/tdei.2018.006938

\section{Published in:}

IEEE Transactions on Dielectrics and Electrical Insulation

\section{Citing this paper}

Please note that where the full-text provided on Manchester Research Explorer is the Author Accepted Manuscript or Proof version this may differ from the final Published version. If citing, it is advised that you check and use the publisher's definitive version.

\section{General rights}

Copyright and moral rights for the publications made accessible in the Research Explorer are retained by the authors and/or other copyright owners and it is a condition of accessing publications that users recognise and abide by the legal requirements associated with these rights.

\section{Takedown policy}

If you believe that this document breaches copyright please refer to the University of Manchester's Takedown Procedures [http://man.ac.uk/04Y6Bo] or contact uml.scholarlycommunications@manchester.ac.uk providing relevant details, so we can investigate your claim.

\section{OPEN ACCESS}




\title{
Streamer Characteristic and Breakdown in a Mineral Oil and a Synthetic Ester Liquid under DC Voltage
}

\author{
J. Xiang, Q. Liu and Z.D. Wang \\ School of Electrical and Electronic Engineering \\ The University of Manchester \\ Manchester M13 9PL, UK
}

\begin{abstract}
This paper presents experimental studies of streamer propagation and breakdown in a mineral oil and a synthetic ester liquid under both positive and negative DC voltages. A point-plane electrode configuration with a tip radius of $10 \mu \mathrm{m}$ was used. Characteristics of streamer length, propagation velocity and shape were analysed based on shadowgraph images obtained at a gap distance of $10 \mathrm{~mm}$ using a multi-channel ultra-high speed camera. Under positive polarity, the streamers in both liquids propagate in the $2^{\text {nd }}$ mode; the stopping length of the synthetic ester is longer than that of the mineral oil at the same applied voltage level. However there is no obvious streamer propagation (less than $10 \%$ of the gap distance) under negative polarity even when the applied voltage approaches to the breakdown voltage; the streamers in both liquids stay in the $1^{\text {st }}$ mode. Breakdown tests at various gaps of $2 \mathrm{~mm}, 5$ $\mathrm{mm}, 10 \mathrm{~mm}, 20 \mathrm{~mm}$ and $30 \mathrm{~mm}$ were also investigated. $50 \%$ breakdown voltages of the synthetic ester liquid are lower than those of the mineral oil at all the gap distances investigated under both polarities.
\end{abstract}

\footnotetext{
Index Terms - Power transformer, DC voltage, streamer, breakdown, mineral oil, synthetic ester
}

\section{INTRODUCTION}

Transformers as one of the major components in high voltage power networks were introduced since the late nineteenth century. In recent years, there are increasing interests in applying High Voltage Direct Current (HVDC) transmission lines, due to their advantages at long distance or submarine bulk energy transmission [1]. In HVDC transmission systems, converter transformers are the essential components. The insulation systems of HVDC converter transformers could suffer from DC biased AC voltage [2]. To understand the streamer and breakdown mechanisms in HVDC converter transformer insulation under combined voltage waveforms, it is worth investigating the phenomena under DC voltage first.

Ester liquids including both natural ester and synthetic ester have been considered as potential alternatives to mineral oils in transformer industries, due to their better environmental performance and higher fire point [3]. Although the ester liquids have been widely employed in distribution \& traction transformers and power transformers up to $400 \mathrm{kV}$ [4], it is still a challenging for the industry to adopt esters in large HVDC converter transformers.

In the past decades, comparisons on streamer and breakdown characteristics between mineral oils and ester liquids under $\mathrm{AC}$ and impulse voltages have been extensively investigated. In quasi-uniform fields (VDE, sphere or plane electrodes), it was reported that breakdown voltages of ester liquids are comparable to those of mineral oils under both $\mathrm{AC}$ $[5,6]$ and impulse voltages [7, 8]. In divergent fields (needleplane electrodes), it was reported that ester liquids have much lower breakdown voltages than mineral oils under impulse voltages $[9,10]$. This is because streamers in ester liquids generally propagate faster and further than those in mineral oils at the same voltage levels [9-12] although the streamer initiation voltages in both liquids are similar [11,13].

There are limited publications comparing the streamer and breakdown phenomena between mineral oils and ester liquids under DC voltage as past studies focused on hydrocarbon liquids. Observation of streamer in hexane under both positive and negative DC voltages was reported in $[14,15]$. The results indicated that negative streamer current waveforms are more regular with an increasing pulse train and positive streamer current waveforms are less regular with intensive pulses superimposed on a continuous current [14, 15]. Similar observations of current waveforms in a synthetic ester liquid under DC voltage was reported in [16]. Effect of pressure on streamer initiation in a synthetic ester liquid under both positive and negative DC voltages was described in [17]. The gaseous nature of streamers was evidenced by increased initiation voltage at a higher pressure [17]. DC breakdown voltages in a mineral oil were presented in [18], showing DC breakdown voltage of positive polarity is much lower than that 
under negative polarity. A study on the effect of DC bias on streamer characteristics of a synthetic ester liquid under step impulse voltage was reported in [19]. The results indicated that a same-polarity dc pre-stress leads to an increased streamer initiation voltage [19]. For polarity reversal, negative dc prestress reduced the positive streamer initiation voltage as expected but positive dc pre-stress increased the negative streamer initiation voltage, which was explained due to the electron 'cleaning' effect [19].

This paper focuses on investigations of streamer propagation and breakdown voltage of a mineral oil and a synthetic ester liquid under both positive and negative DC voltages. A point-plane electrode configuration with a fixed tip radius of $10 \mu \mathrm{m}$ tungsten wire and variable gap distances up to $30 \mathrm{~mm}$ was used. Streamer current was recorded for identifying streamer propagation, breakdown and charge calculation. Hundreds of streamer shadowgraphs are captured by using the high-speed camera to investigate streamer length and shape. Streamer characteristics and breakdown properties of both transformer liquids are compared and discussed.

\section{EXPERIMENTAL DESCRIPTIONS}

\subsection{INVESTIGATED LIQUIDS}

A mineral oil Gemini $X$ and a synthetic ester MIDEL 7131 were investigated in this paper. The ester formulated synthetically by a combination of chemicals. The basic characteristics of these two liquids were presented in the previous publication [10].

The oil samples were directly taken from sealed barrels in oil storage room. Before pre-breakdown and breakdown tests, a well-controlled pre-processing procedure was executed on all insulating liquid samples. Firstly, liquid samples were filtered through a $0.2 \mu \mathrm{m}$ membrane unit to clear away particles. Then, liquid samples were degassed and dehydrated in a vacuum oven under $500 \mathrm{~Pa}$ at $85^{\circ} \mathrm{C}$ for over 48 hours to remove moisture and bubbles. Generally, the relative humidity of processed oil samples is approximately $5 \%$.

\subsection{EXPERIMENTAL SETUP}

The experimental setup used to investigate streamer propagation and breakdown voltages under DC voltage is shown in Figure 1 . A $10 \times 10 \times 10 \mathrm{~cm}$ Perspex made test cell with a volume of 1 litre was used to hold the electrodes and liquid sample. A bipolar high-voltage DC source with a maximum voltage of $100 \mathrm{kV}$ was used to deliver the continuous DC voltage. A $2 \mathrm{M} \Omega$ resistor was placed in series with the DC source and the test cell to limit the breakdown current as well as to protect the high-voltage DC source. A compensated RC voltage divider (VD-100) was used to measure the DC output voltage. A current shunt (10 $\Omega$ ) was placed between the plane electrode of the test cell and the grounding point to record the current signals. The test cell contained a point-to-plane electrode system with an adjustable gap distance ranging from 0 to $50 \mathrm{~mm}$. The point electrodes of tungsten needle with a fixed tip radius of $10 \mu \mathrm{m}$ were produced based on electrochemical technique [20]. All etched tungsten needles were examined and selected by using a microscope to ensure the tip surface is smooth. The plane electrode is a brass electrode with a diameter of $70 \mathrm{~mm}$. All the experiments were carried out at room temperature and ambient pressure.

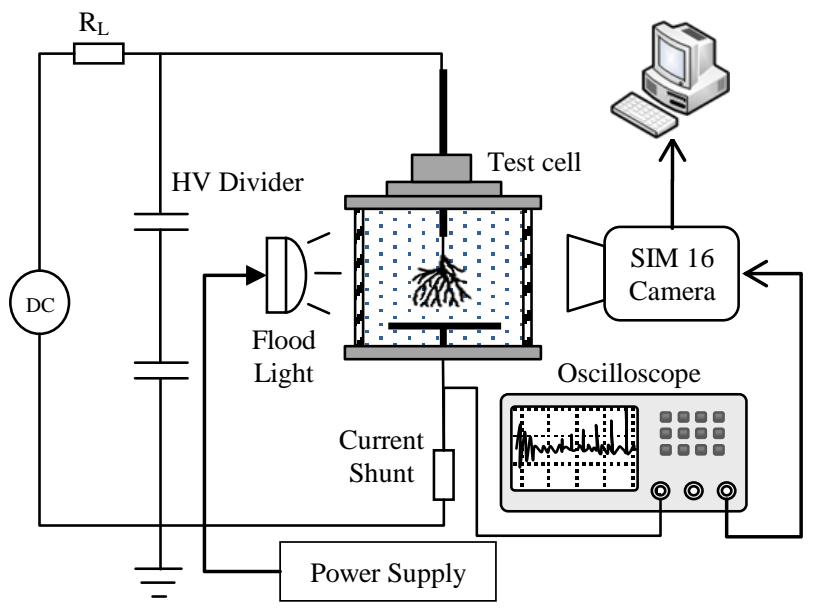

Figure 1. Sketch of the experimental setup.

A 16-channel ultra-high speed camera Specialized Imaging SIM16 with high resolution intensified CCD sensors was used to study streamer characteristics. The high resolution of 1360 $\times 1024$ pixels allows analysing the streamer structure, e.g. stopping length resolution is down to $0.02 \mathrm{~mm}$. Totally 16 frames of photos could be captured. With tuning of time delay, explosion time, aperture value and the distance to the flood light, the shadowgraph image quality was optimised.

The oscilloscope with a bandwidth of $1 \mathrm{GHz}$ is not only used for recording voltage and current signals but also used to synchronously trigger the high-speed camera. Once there is a streamer current triggered in the oscilloscope, a $5 \mathrm{~V}$ TTL signal will be sent out from the oscilloscope to trigger the camera.

\section{POSITIVE STREAMER}

Studies of positive streamer characteristics including streamer current, stopping length, propagation velocity, shape and charge were carried out at the $10 \mathrm{~mm}$ gap distance.

\subsection{TYPICAL POSITIVE STREAMER}

Streamer propagation was studied by using a rising-voltage procedure. The initial voltage was applied at streamer inception voltage level. Then, the applied voltage was increased in steps of $5 \mathrm{kV}$. At each voltage level, a series of ten different streamer shadowgraphs were captured by the high-speed camera. To avoid the cumulative effect of continuing DC voltage stress on oil sample, a minimum of 60second interval was allowed between each streamer capture.

An example of the current signal and shadowgraph of positive streamer propagation in the synthetic ester liquid at 
the gap distance of $10 \mathrm{~mm}$ is shown in Figure 2. The current signal is intensive and consists of continuous current components superimposed with large discrete pulses. A camera monitor signal was used to correlate the streamer shadowgraph and the current signal. Streamer propagation based on shadowgraphs is shown in Figure 2b, where only one main branch with small offshoots was observed. A clearly growing path of the main branch was observed from frame 1 to frame 3. The streamer tip continued propagation for a short distance even after the current pulses ended, as shown in frame 4. At this stage, it was observed that the initial channel, root, of the streamer, has dissipated into the liquid where the streamer tip propagation continues due to either the local ionisation or simply gaseous channel expansion. Similar phenomenon was reported in [15]. The final stopping length of streamer based on Figure 2b (Frame 4) is $7.34 \mathrm{~mm}$ with average propagation velocity of $1.56 \mathrm{~km} / \mathrm{s}$.

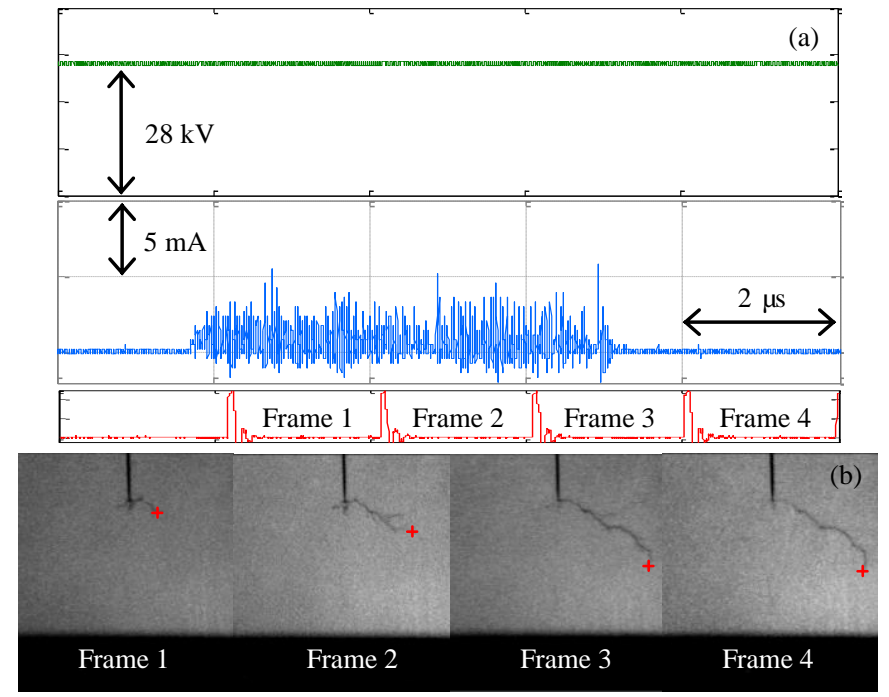

Figure 2. Typical positive streamer propagation in the synthetic ester liquid under DC voltage, $d=10 \mathrm{~mm}, r=10 \mu \mathrm{m}, V=28 \mathrm{kV}$; (a) voltage, current and monitor signals, (b) streamer propagation, corresponding to the signals in (a).

\subsection{STOPPING LENGTH}

The results of streamer stopping length in the mineral oil and the synthetic ester liquid at a $10 \mathrm{~mm}$ gap under positive polarity are shown in Figure 3. 50\% breakdown voltages, determined using step-by-step rising voltage method as detailed in section 5.2, are also stated as reference in Figure 3 $\left(\mathrm{V}_{\mathrm{B} \text {-Gemini } \mathrm{X}}\right.$ and $\mathrm{V}_{\mathrm{B} \text {-MIDEL } 7131}$ stand for $50 \%$ breakdown voltage of the mineral oil and the synthetic ester liquid respectively, the same as in Figure 4, Figure 7 and Figure 8). At each voltage level, the mean and standard deviation are given based on 10 measurements.

Under positive polarity, the synthetic ester liquid behaves similarly to the mineral oil at inception voltage level $V=15$ $\mathrm{kV}$, which is similar to that observed under impulse voltage $[11,13]$. The stopping length of both liquids increases gradually with the increase of applied voltage. When applied voltage is higher than $15 \mathrm{kV}$, the stopping length of the synthetic ester liquid becomes longer than that of the mineral oil. The higher average increasing rate, $\mathrm{mm} / \mathrm{kV}$, of the synthetic ester liquid, resulting in a lower breakdown voltage compared with the mineral oil. Figure $3 b$ shows the fully propagated streamers at the different voltage levels in both liquids. It is clear that higher voltage level indeed promotes streamer growth in terms of length, whereas it does not have much effect on branching in the investigated range.

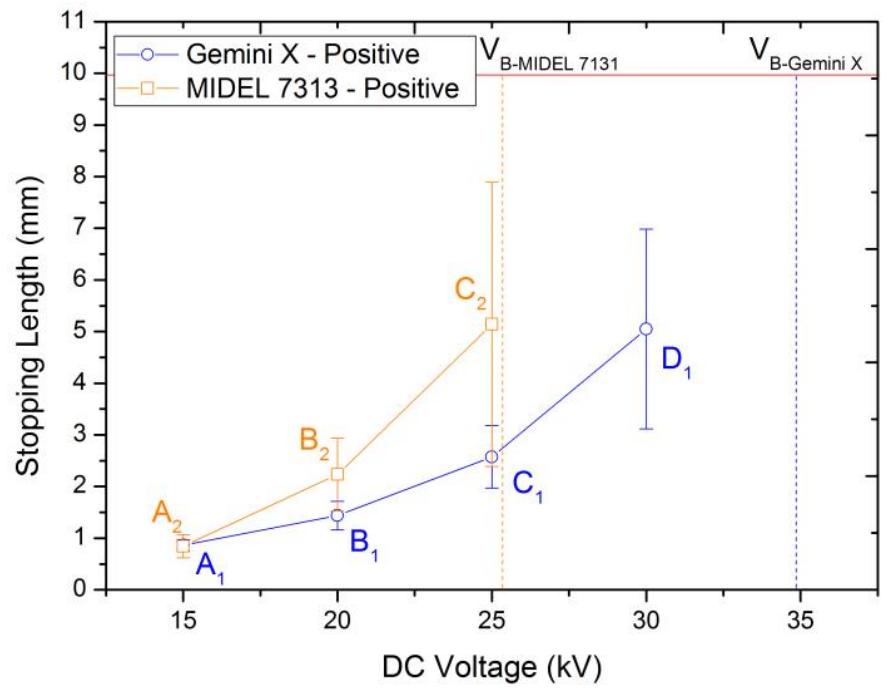

(a) Streamer stopping length versus applied DC voltage

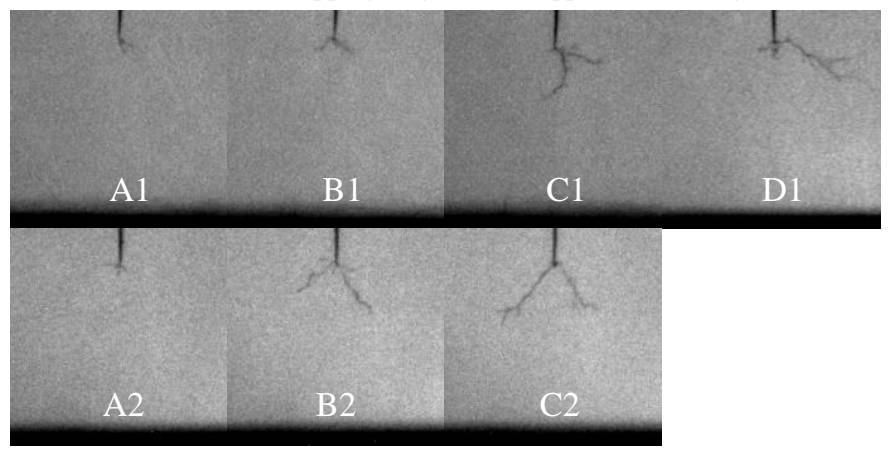

(b) Corresponding streamer shape at different voltage levels

Figure 3. Stopping length of streamers in the mineral oil and the synthetic ester liquid under positive polarity, $d=10 \mathrm{~mm}, r=10 \mu \mathrm{m}$ (error bars stand for one standard deviation).

\subsection{PROPAGATION VELOCITY}

Average streamer propagation velocity $v_{a}$, is calculated by the ratio of stopping length $l$ to propagating time $t$. The propagating time $t$ is determined by the duration of streamer current signals. Once breakdown occurs, $v_{\mathrm{a}}$ is determined by using the gap distance $d$ divided by time to breakdown $t_{\mathrm{b}}$.

Figure 4 shows the comparison of average streamer propagation velocity in the mineral oil and the synthetic ester liquid at a $10 \mathrm{~mm}$ gap distance under positive polarity. It is found that average propagation velocity in the synthetic ester liquid is comparable to that in the mineral oil, remaining in the range from $1.5 \mathrm{~km} / \mathrm{s}$ to $2 \mathrm{~km} / \mathrm{s}$. 


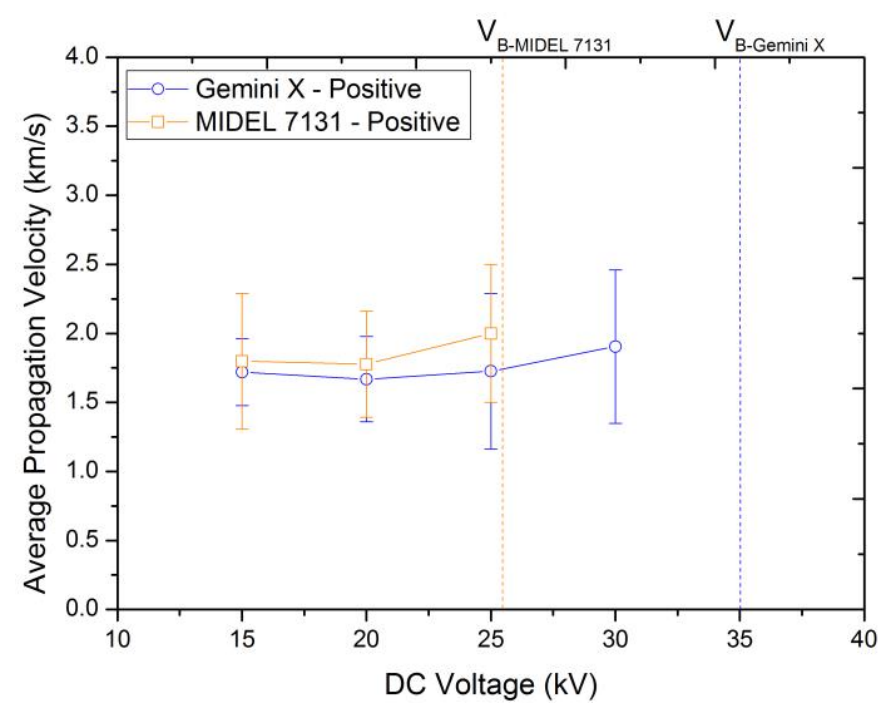

Figure 4. Average propagation velocity versus applied DC voltage in the mineral oil and the synthetic ester liquid under positive polarity, $d=10 \mathrm{~mm}, r$ $=10 \mu \mathrm{m}$ (error bars stand for one standard deviation).

\subsection{STREAMER CHARGE}

The apparent charge from PD measurement serves as a key indicator of insulation defect. This raises the question of whether the apparent charge threshold adopted can suitably reflect the presence of streamers in liquids under DC voltage.

Synchronised measurements of streamer shape and current allow the correlations between stopping length (shown in Figure 3) and maximum apparent charge (calculated based on the integration of current signals over time) to be established. Figure 5 shows the positive streamer stopping length as a function of maximum apparent charge in both the mineral oil and the synthetic ester liquid under positive DC voltage. The results indicate that the correlations between streamer stopping lengths and apparent charges increase linearly in both the mineral oil and the synthetic ester liquid. The rate is about $0.31 \mathrm{~mm}$ per $100 \mathrm{pC}$ in the mineral oil and $0.26 \mathrm{~mm}$ per 100 $\mathrm{pC}$ in the synthetic ester liquid.

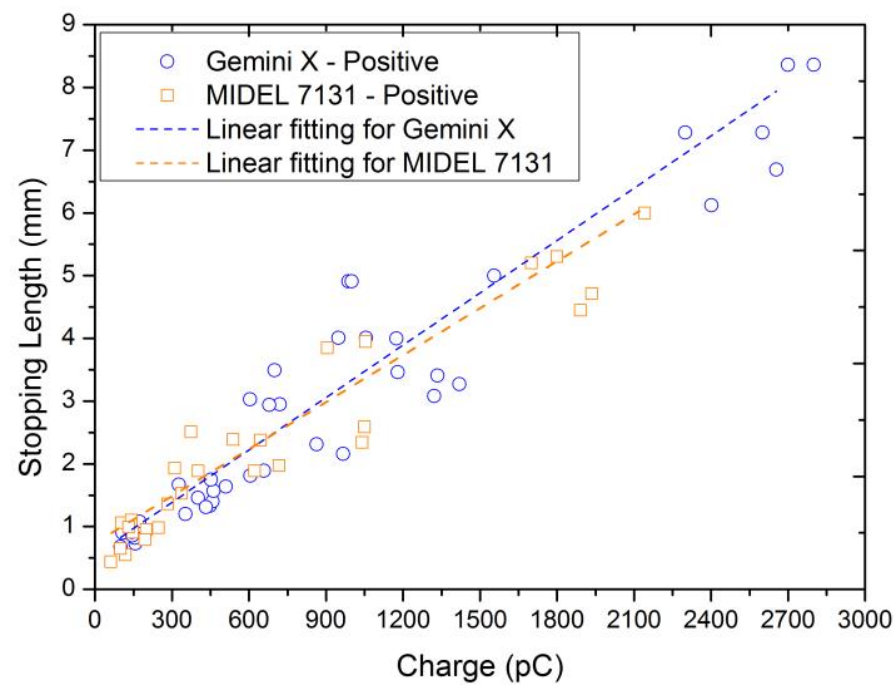

Figure 5. Positive streamer stopping length as a function of maximum apparent charge in the mineral oil and the synthetic ester liquid.

\section{NEGATIVE STREAMER}

Study of negative streamer characteristics including streamer current, stopping length, propagation velocity, shape, and charge was carried out at the $10 \mathrm{~mm}$ gap distance as well.

\subsection{TYPICAL NEGATIVE STREAMER}

A similar experimental procedure was carried out under negative polarity. Figure 6 shows an example of the current signal and shadowgraph of negative streamer propagation in the synthetic ester liquid at the gap distance of $10 \mathrm{~mm}$. A train of clearly recognised discrete pulses with increasing amplitude is observed in current signal, which is similar to the previous finding of the negative streamer in ester liquids observed under dc [16], ac [21] and impulse voltages [9, 11, 12]. A camera monitor signal was used to correlate the streamer shadowgraph and the current signal. Streamer propagation based on shadowgraphs is shown in Figure 6b. Different to the streamer observed under positive polarity, the negative streamer slowly propagates in the form of cloud-shape from frame 1 to frame 5, and its dissipation is also slower than positive streamer after the end of the current signal. The final stopping length of the streamer based on Figure 6b (Frame 5) is $1.13 \mathrm{~mm}$, with an average propagation velocity of $0.12 \mathrm{~km} / \mathrm{s}$.
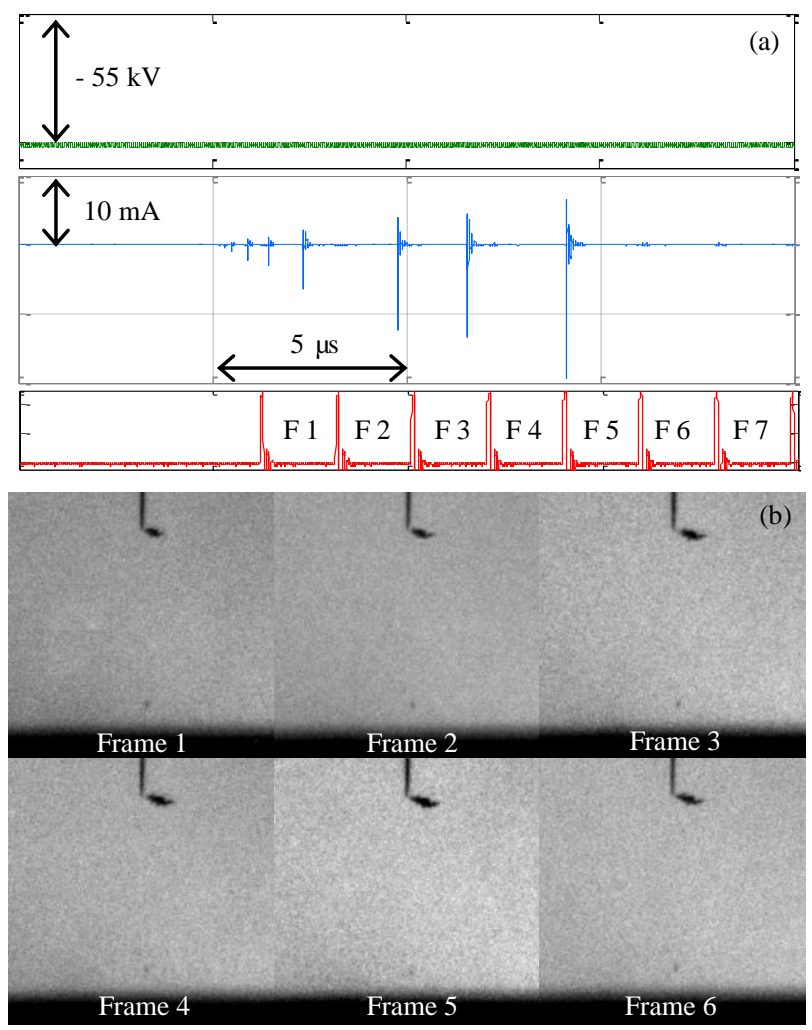

Figure 6. Typical negative streamer propagation in the synthetic ester liquid under DC voltage, $d=10 \mathrm{~mm}, r=10 \mu \mathrm{m}, V=-55 \mathrm{kV}$; (a) voltage, current and camera monitor signals, (b) streamer propagation, corresponding to the signals in (a). 


\subsection{STOPPING LENGTH}

Figure 7 shows the streamer stopping length in the mineral oil and the synthetic ester liquid at a $10 \mathrm{~mm}$ gap under negative polarity. Under negative polarity, a significant difference of the streamer stopping length characteristic exists in both liquids compared to the positive polarity. The streamers in both liquids increase extremely slowly from inception voltage to the voltage before breakdown. Stopping length of only about $1 \mathrm{~mm}$ can be observed in the synthetic ester liquid at the applied voltage of $50 \mathrm{kV}\left(\mathrm{V}_{\mathrm{B}-\mathrm{MIDEL}} 7131=\right.$ $59.8 \mathrm{kV}$ ), and only about $0.7 \mathrm{~mm}$ for the mineral oil at the applied voltage of $80 \mathrm{kV}\left(\mathrm{V}_{\mathrm{B} \text {-Gemin } \mathrm{X}}=92.9 \mathrm{kV}\right)$. The stopping lengths of negative streamers of the synthetic ester liquid are longer than those of the mineral oil. The higher average increasing rate, $\mathrm{mm} / \mathrm{kV}$, of the synthetic ester liquid, results in a lower breakdown voltage compared with the mineral oil.

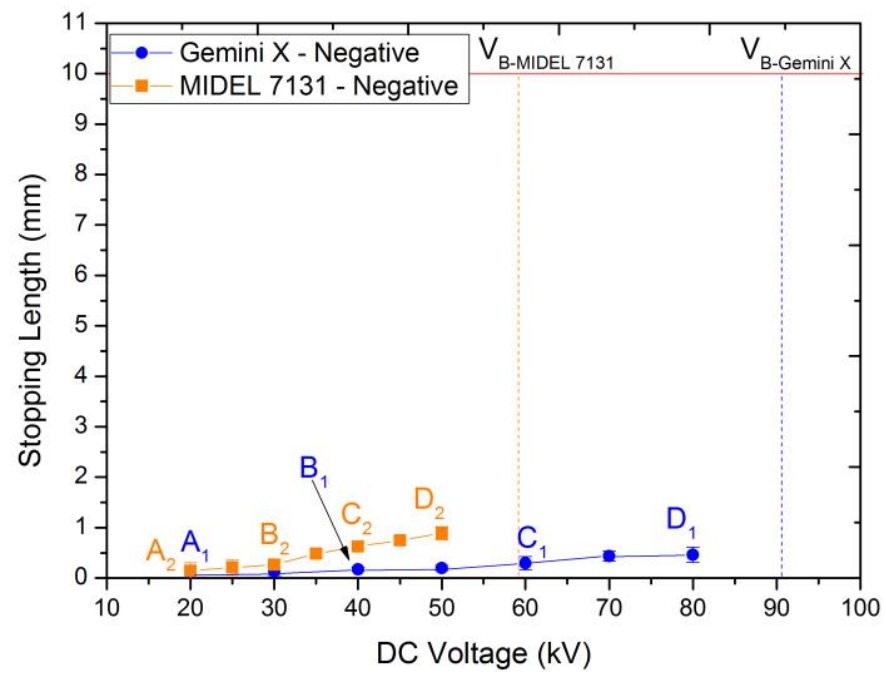

(a) Streamer stopping length versus applied DC voltage

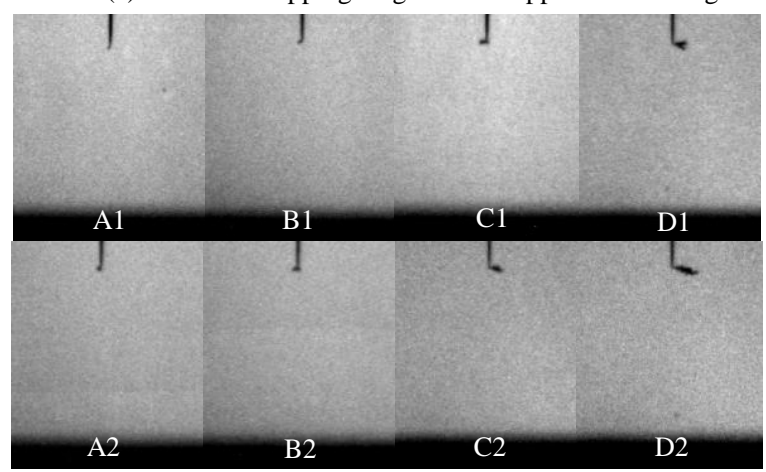

(b) Streamer area versus applied DC voltage

Figure 7. Stopping length of streamers in the mineral oil and the synthetic ester liquid under negative polarity, $d=10 \mathrm{~mm}, r=10 \mu \mathrm{m}$ (error bars stand for one standard deviation).

Figure $7 \mathrm{~b}$ shows the fully propagated streamers at the different voltage levels in both the liquids. At the inception voltage level $\left(A_{1}\right.$ and $\left.A_{2}\right)$, only a tiny streamer tip around the point electrode is observed in both the liquids. At the voltage level before breakdown $\left(D_{1}\right.$ and $\left.D_{2}\right)$, the negative streamers barely propagate (stopping length $<\sim 0.1 d$ ) and are in the form of cloud-shape with no clear branch and offshoot. This is obviously different from the negative streamer characteristics observed under impulse voltages, where the stopping length increases exponentially with increase of applied voltage [9-12]. After ionisation occurs near the streamer tip region, the dissipated negative space charges seem to form a strong shielding effect and hence weaken the boundary field, which prevents further propagation of the streamer.

\subsection{PROPAGATION VELOCITY}

Figure 8 shows the comparison of average streamer propagation velocity in the mineral oil and the synthetic ester liquid at a $10 \mathrm{~mm}$ gap under negative polarity. At the inception voltage levels, there is only one single pulse of the current signal that was captured for the negative streamer. The propagation time based on the current signal is thus extremely short, from about $50 \mathrm{~ns}$ to $200 \mathrm{~ns}$. In addition, the streamer length at this stage is also extremely short, so there is uncertainty of calculating the streamer velocity. With the increase of applied voltage, the propagation time is measured based on multiple current pulses, the average propagation velocity can then be reasonably calculated based on the ratio of the stopping length to the propagation time. It is found that the negative streamer velocity in the synthetic ester liquid is comparable to that in the mineral oil, remaining in the range from $0.1 \mathrm{~km} / \mathrm{s}$ to $0.3 \mathrm{~km} / \mathrm{s}$, which corresponds to the $1^{\text {st }}$ mode of streamer propagation [22].

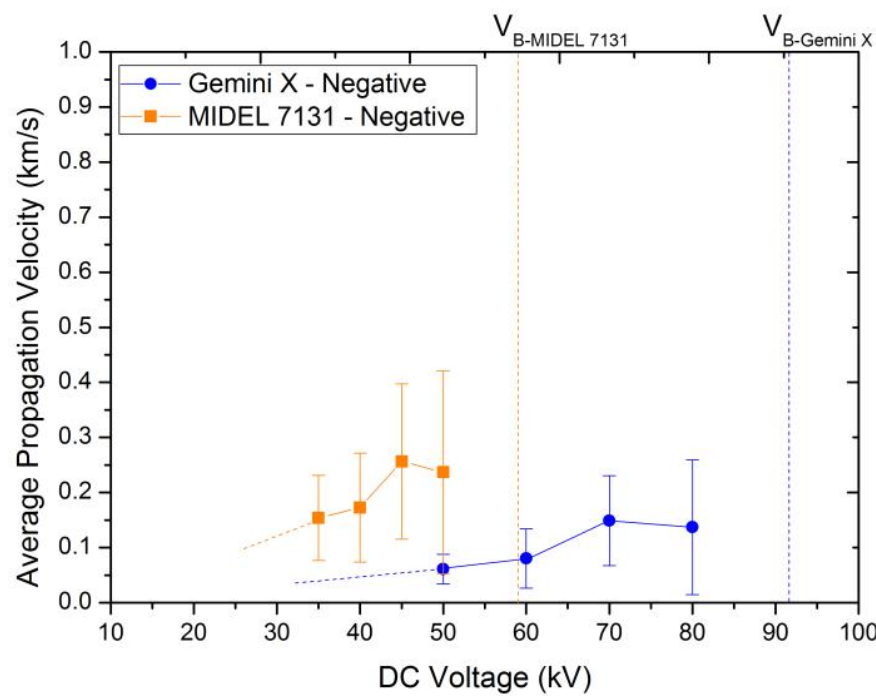

Figure 8. Average propagation of streamers in the mineral oil and the synthetic ester liquid under negative polarity, $d=10 \mathrm{~mm}, r=10 \mu \mathrm{m}$ (error bars stand for one standard deviation).

\subsection{STREAMER CHARGE}

Figure 9 shows the negative streamer stopping length as a function of maximum apparent charge in both the mineral oil and the synthetic ester liquid. Different to the linear relationship under positive polarity, the apparent charge firstly increases with the increase of stopping length, and then the increase rate slows down when the apparent charge above $50 \mathrm{pC}$. This result indicates that although the streamer does not propagate much further as shown in stopping length, but the discharge becomes more intensive as shown in charge. 


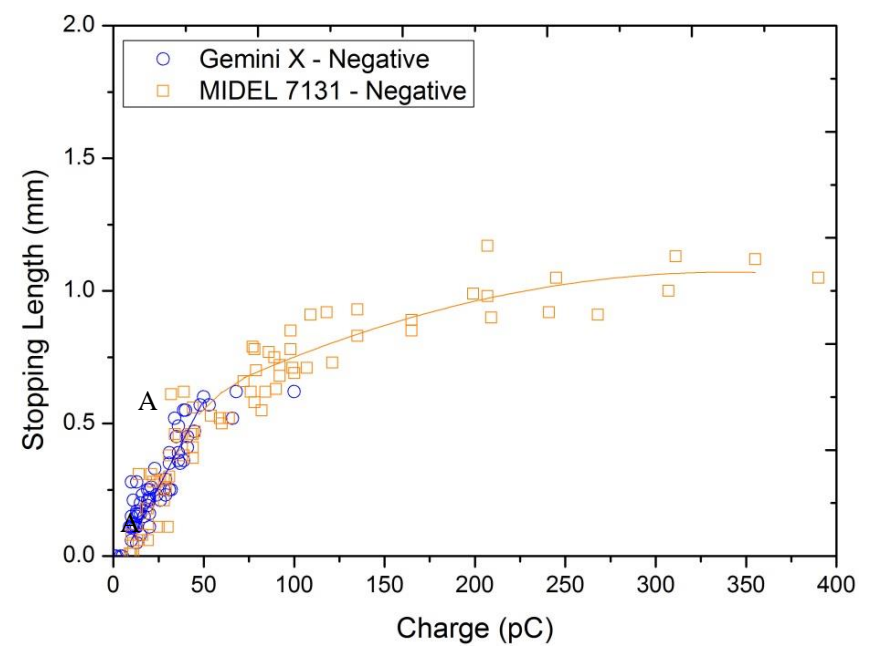

Figure 9. Negative streamer stopping length as a function of maximum apparent charge in the mineral oil and the synthetic ester liquid.

\section{BREAKDOWN VOLTAGE}

\subsection{BREAKDOWN PHENOMENON}

Figure 10 shows an example of the streamer leading to the breakdown in the synthetic ester liquid under positive polarity. A series of intensive pulses superimposed on a continuous current are commonly observed for the positive streamer. Compared with the current signal of pre-breakdown phenomena, the current signal becomes gradually stronger with increasing amplitude. At about $8 \mu \mathrm{s}$, the streamer propagated to the opposite plane electrode with one main branch with strong luminance indicates the breakdown event, as shown in Figure 10b (frame 4).
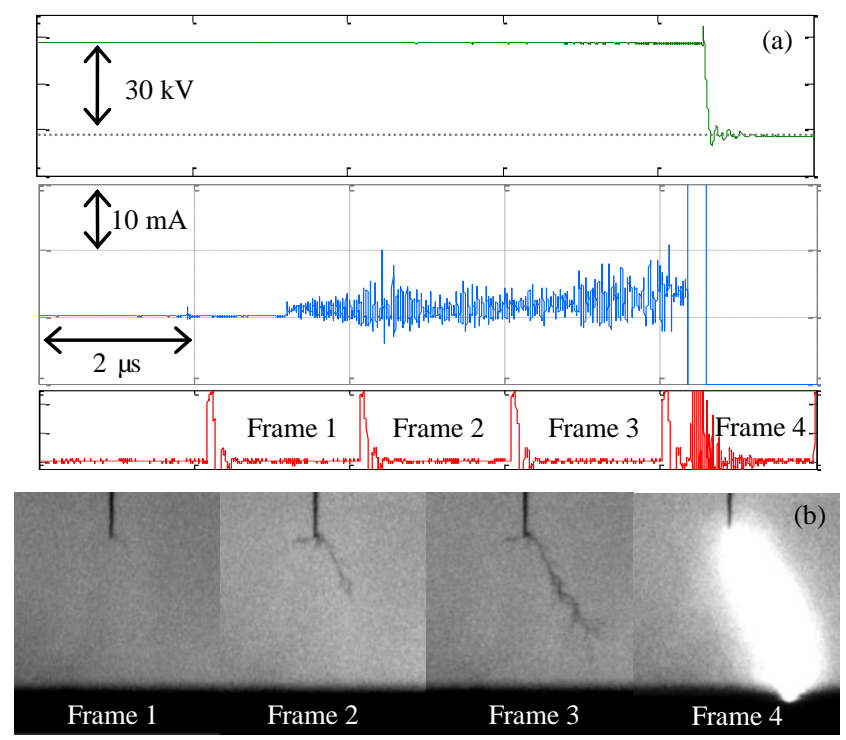

Figure 10. Breakdown in the synthetic ester liquid under positive polarity; $d$ $=10 \mathrm{~mm}, r=10 \mu \mathrm{m}$, exposure time $2 \mu \mathrm{s}$.

Figure 11 shows the streamer leading to the breakdown in the synthetic ester liquid under negative polarity. A long current train with discrete pulses is observed before breakdown. A few small discrete current pulses with relatively low amplitude existed before frame 1 as shown in the black dashed circle A in Figure 11a. The amplitude of these small discrete pulses is nearly equal to the current amplitude $(\approx 10$ $\mathrm{mA}$ ) shown in Figure 6a. The average propagation velocity of the breakdown event is about $1.01 \mathrm{~km} / \mathrm{s}$, which belongs to the $2^{\text {nd }}$ mode streamer. This result indicates that the negative streamer changes from the $1^{\text {st }}$ mode streamer in Figure 8 to the $2^{\text {nd }}$ mode streamer in Figure 11 at the breakdown level. Comparing between Figure 10b and Figure 11b, the negative streamer is clearer and much thicker, and it has more branches with many small offshoots than the positive streamer.

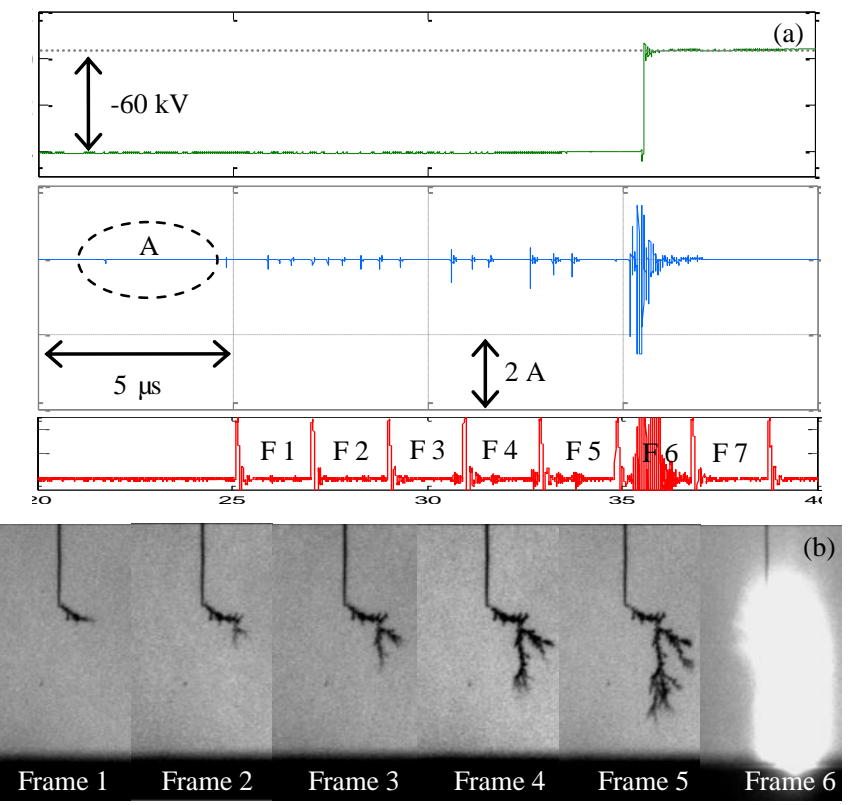

Figure 11. Breakdown in the synthetic ester liquid under negative polarity; $d$ $=10 \mathrm{~mm}, r=10 \mu \mathrm{m}$, exposure time $2 \mu \mathrm{s}$.

\subsection{BREAKDOWN VOLTAGE}

The breakdown voltage was measured by using a rising voltage method. The initial voltage applied was set at $70 \%$ of expected breakdown voltage. The voltage level was increased step by step with a step voltage of $2 \mathrm{kV}$. For each step of applied DC voltage, 60-second duration was applied to allow the capturing of breakdown, and a minimum of 120-second interval was used between each step. Twenty breakdowns per sample were obtained to determine the $50 \%$ breakdown voltage at a gap distance of $10 \mathrm{~mm}$.

To statistically analyse the breakdown voltage, twoparameter Weibull distribution was used to fit the breakdown results and to calculate $50 \%$ breakdown voltage. Figure 12 shows the breakdown results of the mineral oil and the synthetic ester liquid under both positive and negative polarities, and Weibull parameters are summarised in Table 1. Strong polarity effect was observed, breakdown voltages of negative polarity are nearly 2.5 times of that of positive polarity. This conclusion is valid for both the mineral oil and the synthetic ester. The reason is, under positive polarity, the concentration of positive charges enhanced the boundary field at the head of the charge cloud, which promotes streamer 
propagation and then weakens breakdown voltages. However, the diluted negative space charges, like a shielding of the negative tip, weaken the boundary field, which slows down the streamer propagation and hence increases the negative breakdown voltage.

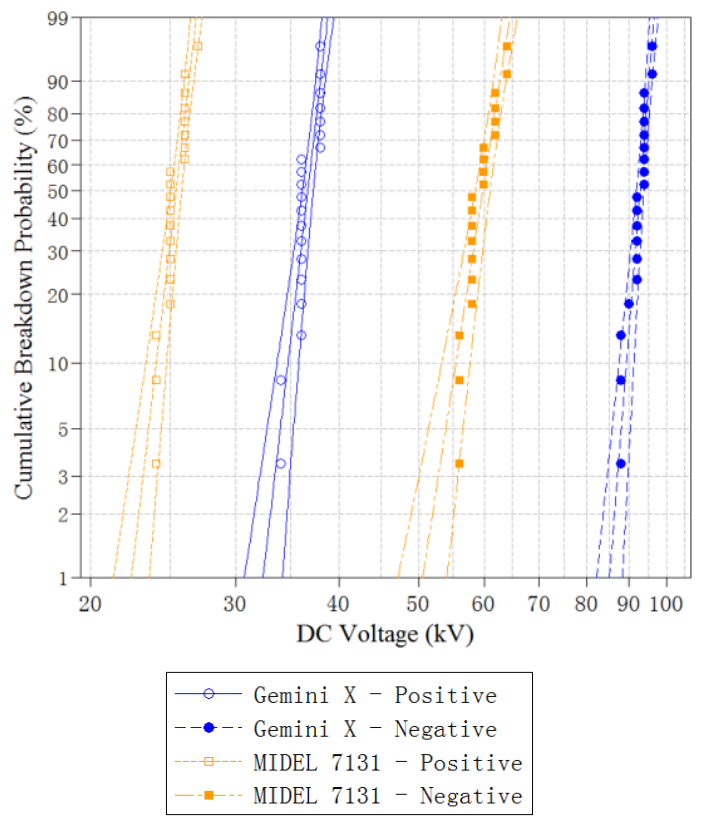

Figure 12. Weibull distribution plot of breakdown results in the mineral oil and the synthetic ester liquid under DC voltage, $d=10 \mathrm{~mm}, r=10 \mu \mathrm{m}$.

Table 1. Weibull parameters of breakdown results in the mineral oil and the synthetic ester liquid under DC voltage, point-plane electrode, $d=10 \mathrm{~mm}, r=$ $10 \mu \mathrm{m}$.

\begin{tabular}{ccccc}
\hline Oil Type & Polarity & Shape & Scale & $\begin{array}{c}\text { 50\% Breakdown } \\
\text { Voltage }(\mathbf{k V})\end{array}$ \\
\hline Mineral Oil & Positive & 33.9 & 37.1 & 35.7 \\
\cline { 2 - 5 } & Negative & 49.3 & 93.6 & 92.9 \\
\hline $\begin{array}{c}\text { Synthetic Ester } \\
\text { Liquid }\end{array}$ & Positive & 33.7 & 25.7 & 25.4 \\
\cline { 2 - 5 } & Negative & 25.2 & 60.7 & 59.8 \\
\hline
\end{tabular}

\subsection{EFFECT OF GAP DISTANCE ON BREAKDOWN VOLTAGE}

Twenty breakdowns per sample were obtained to determine the $50 \%$ breakdown voltage based on two-parameter Weibull distribution under gap distances of $2 \mathrm{~mm}, 5 \mathrm{~mm}, 10 \mathrm{~mm}, 20$ $\mathrm{mm}$ and $30 \mathrm{~mm}$.

The effect of gap distance on breakdown voltages under both positive and negative DC voltages are shown in Figure 13. It is clear that breakdown voltages of both positive and negative polarities almost increase linearly with the gap distance in the investigated range. In the mineral oil, the breakdown voltages of negative polarity are about 2.5 times higher than those under positive polarity. In synthetic ester liquid, the breakdown voltages of negative polarity are about 2.2 times higher than those under positive polarity. Under both positive and negative polarities, the breakdown voltages of the mineral oil are about 1.5 times higher than those of the synthetic ester.

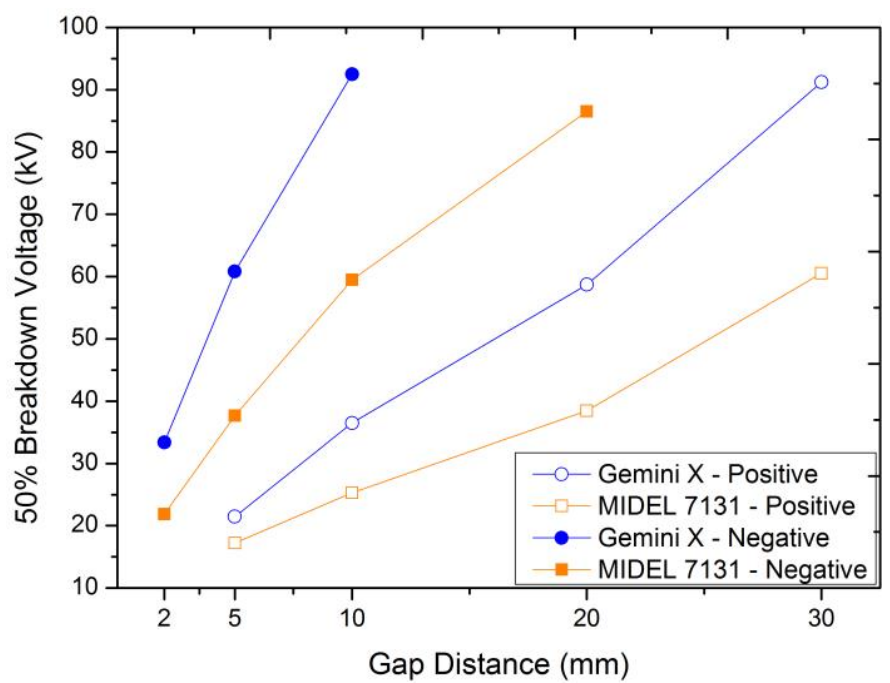

Figure 13. Effect of gap distance on breakdown voltage in the mineral oil and the synthetic ester liquid under DC voltage, $r=10 \mu \mathrm{m}$; based on $50 \%$ breakdown voltages.

\section{CONCLUSION}

In this paper, streamer characteristics and breakdown strength of the mineral oil and the synthetic ester liquid under both positive and negative DC voltages in the divergent fields were studied.

The stopping length of positive streamers gradually increases with the applied voltage. However, the negative streamer remains in the $1^{\text {st }}$ mode and barely propagates with the increase of applied voltage, which is different from those observed in previous studies under impulse voltage [9-12].

The apparent charge is correlated to streamer length. The correlations between streamer stopping lengths and apparent charges increase linearly in both the liquids under positive polarity, whereas it shows non-linear relationship under negative polarity. In the investigated range, there is no obvious difference of streamer shape between the mineral oil and the synthetic ester liquid and hence the correlations between streamer stopping lengths and apparent charges are identical in both liquids.

\section{ACKNOWLEDGMENT}

The authors would like to acknowledge the use of Specialised Imaging SIM 16 Camera which was borrowed from the EPSRC (Engineering and Physical Sciences Research Council) Engineering Instrument Pool.

\section{REFERENCES}

[1] M. H. Okba, M. H. Saied, M. Z. Mostafa, and T. M. Abdel-Moneim, "High voltage direct current transmission - A review, part I," IEEE Energytech 2012, Cleveland, OH, USA, May 2012.

[2] M. H. Okba, M. H. Saied, M. Z. Mostafa, and T. M. Abdel-Moneim, "High voltage direct current transmission - A review, part II - Converter technologies," IEEE Energytech 2012, Cleveland, OH, USA, May 2012. 
[3] L. Lewand, "Laboratory evaluation of several synthetic and agriculturalbased dielectric liquids", Doble Int. Client Conference, Boston, USA, March, 2001.

[4] Paul Jarman, Kevin Hampton, Mark Lashbrooke and Georg J. Pukel, "Reliable, optimised power transformers with heat recovery for urban areas," Transformers Magazine, vol. 4, no. 2, pp. 84-90, 2017

[5] V. H. Dang, A. Beroual, and C. Perrier, "Comparative study of statistical breakdown in mineral, synthetic and natural ester oils under AC voltage," IEEE Transactions on Dielectrics and Electrical Insulation, vol. 19, no. 5, pp. 1508-1513, 2012.

[6] X. Wang, and Z.D. Wang, "Study of dielectric behavior of ester transformer liquids under ac voltage," IEEE Transactions on Dielectrics and Electrical Insulation, vol. 19, no. 6, pp. 1916-1925, 2012.

[7] Q. Liu, and Z.D. Wang, "Breakdown and withstand strengths of ester transformer liquids in a quasi-uniform field under impulse voltages," IEEE Transactions on Dielectrics and Electrical Insulation, vol. 20, no. 2, pp. 571-579, 2013.

[8] W. Lu, and Q. Liu, "Effect of cellulose particles on impulse breakdown in ester transformer liquids in uniform electric fields," IEEE Transactions on Dielectrics and Electrical Insulation, vol. 22, no. 5, pp. 2554-2564, 2015.

[9] C. T. Duy, O. Lesaint and A. Denat, "Streamer propagation and breakdown in natural ester at high voltage," IEEE Transactions on Dielectrics and Electrical Insulation, vol. 16, no. 6, pp. 1582-1594, 2009.

[10] Q. Liu, and Z.D. Wang, "Streamer characteristic and breakdown in synthetic and natural ester transformer liquids under standard lightning impulse voltage," IEEE Transactions on Dielectrics and Electrical Insulation, vol. 18, no. 1, 2011.

[11] V.-H. Dang, A. Beroual and C. Perrier, "Investigations on streamers phenomena in mineral, synthetic and natural ester oils under lightning impulse voltage," IEEE Transactions on Dielectrics and Electrical Insulation, vol. 19, no. 1521-1527, 2012.

[12] P. Rozga, "Streamer propagation in small gaps of synthetic ester and mineral oil under lightning impulse," IEEE Transactions on Dielectrics and Electrical Insulation, vol. 22, no. 5, pp. 2754-2762, 2015.

[13] P. Rozga, and M. Stanek, "Characteristics of streamers developing at inception voltage in small gaps of natural ester, synthetic ester and mineral oil under lightning impulse," IET Science, Measurement \& Technology, vol. 10, no. 1, pp. 50-57, 2016.

[14] K. Stricklett, C. Fenimore and E. Kelly, "Observation of partial discharge in hexane under high magnification," IEEE Transactions on Electrical Insulation, vol. 26, no. 4, pp. 692-698, 1991.

[15] E. Kelley, M. Nehmadi and R. Hebner, "Measurement of partial discharges in Hexane under dc voltage," IEEE Transactions on Electrical Insulation, vol. 24, no. 6, pp. 1109-1119, 1989.

[16] B. Lehouidj, S. Sahra and A. Nacer, "Streamer currents, emitted lights and energies into dielectric liquids submitted to DC stress." IEEE International Conference on Dielectric Liquids (ICDL), pp. 1-4, Bled, Slovenia, 2014

[17] Aka-Ngnui, A. Beroual and C. Perrier, "Pre-breakdown phenomena in synthetic ester and silicone oils for power transformers," IEEE International Conference on Dielectric Liquids(ICDL), pp. 1-4, Futuroscope-Chasseneuil, France, 2008.

[18] Y. Du, Y. Lv and C. Li, "Effect of Semiconductive Nanoparticles on Insulating Performances of Transformer Oil," IEEE Transactions on Dielectrics and Electrical Insulation, vol. 19, no. 3, pp. 770-776, 2012.
[19] M. T. Do, A. Nysveen and L. E. Lundgaard, "An experimental study on the effect of DC bias on streamer initiation and propagation in a dielectric liquid under impulse voltage," IEEE Transactions on Dielectrics and Electrical Insulation, vol. 16, no. 6, pp. 1623-1631, 2009.

[20] W.-T. Chang, I.-S. Hwang and M.-T. Chang, "Method of electrochemical etching of tungsten tips with controllable profiles," Review of Scientific Instruments, vol. 83, no. 8, pp. 083704, 2012.

[21] J. Xiang, and Q. Liu, "Current and emitted light characteristics of streamers in insulating liquids under ac voltages," 19th International Symposium on High Voltage Engineering (ISH), pp. 295, Pilsen, Czech Republic, 2015.

[22] O. Lesaint, "Prebreakdown phenomena in liquids: propagation 'modes' and basic physical properties," Journal of Physics D: Applied Physics, vol. 49, no. 14, pp. 144001, 2016.

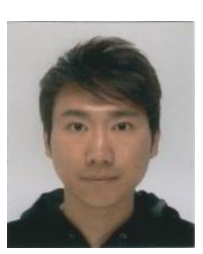

Jing Xiang obtained the B.Sc. degree in electrical and electronic engineering (2013) from The University of Manchester in the UK. Currently, he is a Ph.D student at the Power and Energy Division in the School of Electrical and Electronic Engineering at the University of Manchester. His research interest is the pre-breakdown (streamer) and breakdown mechanism investigation of insulating liquids under different voltage stresses.

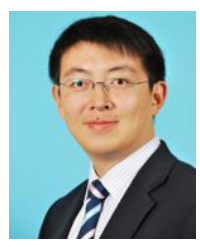

Qiang Liu (S'08-M'12) obtained the B.Eng. degree in electrical engineering (2005) and the M.Eng degree in high voltage and electrical insulation (2008) from Xi'an Jiaotong University (XJTU) in China, and the Ph.D. degree in electrical power engineering (2011) from The University of Manchester in the UK. Currently, he is a Senior Lecturer in the Power and Energy Division in the School of Electrical and Electronic Engineering at The University of Manchester. His research interests are on pre-breakdown and breakdown phenomena in liquids, alternative transformer liquids, streaming electrification, ageing of insulating materials, thermal modelling, transformer asset management and high voltage testing.

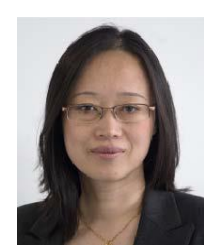

Zhongdong Wang received the B.Eng. and the M.Eng. degrees in high voltage engineering from the Tsinghua University of Beijing in 1991 and 1993 respectively and the Ph.D. degree in electrical engineering from UMIST in 1999. Currently, she is a Professor of High Voltage Engineering in the Power and Energy Division of the School of Electrical and Electronic Engineering at The University of Manchester. Her current research interests include transformer condition monitoring, transformer modelling, FRA, transients' simulation, insulation ageing and alternative insulation materials for transformers. 